\title{
Understanding the Crystallization Mechanism of a Wollastonite Base Glass Using Isoconversional, IKP Methods and Master Plots
}

\author{
Juan M. Pérez, ${ }^{\ddagger}$ Silvio R. Teixeira, ${ }^{\S}$ Jesús Ma. Rincón, ${ }^{\ddagger}$ and Maximina Romero ${ }^{\ddagger \dagger}$ \\ ${ }^{*}$ Group of Glassy and Ceramic Materials, Instituto de Ciencias de la Construcción Eduardo Torroja, \\ CSIC, Madrid 28033, Spain \\ ${ }^{\S}$ Departamento Fisica, Quimica e Biologia, Universidade Estadual Paulista-UNESP, Presidente Prudente, \\ Säo Paulo 19060-080, Brazil
}

\begin{abstract}
The complex development of crystals found in the crystallization of $\mathrm{SiO}_{2}-\mathrm{Al}_{2} \mathrm{O}_{3}-\mathrm{CaO}-\mathrm{Na}_{2} \mathrm{O}$ glass has been explained using Differential Thermal Analysis. The crystal growth process has been studied using isoconversional, invariant kinetic parameters, and master plots methods. The applied kinetic models have revealed activation energy values that are over 360 and $385 \mathrm{~kJ} / \mathrm{mol}$ by employing the integral and differential kinetic methods, respectively. The crystallization process schedule that was previously observed using scanning electron microscopy has been corroborated in this study using the kinetic methods. The crystallization of wollastonite occurs through a complex two-stage mechanism, with early threedimensional growth of crystals $\left(A_{3}\right.$ mechanism) on the surface of glass particles followed by one-dimensional growth of needles $\left(\mathbf{A}_{3 / 2}\right.$ mechanism) toward the interior of grains. The results presented in this article are in agreement with a previous paper that employed the Kissinger non-isothermal method and the Ligero approximation.
\end{abstract}

\section{Introduction}

G LASS-CERAMICS are materials that contain small crystals embedded in a glassy matrix. The key to improving and controlling the final properties of these materials lies in the shape of and the way these crystals are developed in the parent glass. The most common way to produce a glassceramic is through a controlled crystallization process that involves two steps: nucleation and crystal growth. In the former, small nuclei are developed on the surface and/or in the bulk glass; and in the latter, these nuclei, or small crystals, grow to a suitable size.

The $\mathrm{SiO}_{2}-\mathrm{Al}_{2} \mathrm{O}_{3}-\mathrm{CaO}$ system is one of the most known and studied for glass-ceramics production, ${ }^{1}$ as base glasses of this system are suitable for producing glass-ceramics with wollastonite $\left(\mathrm{CaO} \cdot \mathrm{SiO}_{2}\right)$ as the main crystalline phase, according to a mechanism of controlled surface crystallization. At temperatures above $950^{\circ} \mathrm{C}$, base glasses of this system exhibit the crystallization of $\beta$-wollastonite on the surface, and at $1000^{\circ} \mathrm{C}$, wollastonite begins to grow as needles from the edge to the interior of the bulk glass. If the temperature rises to $1180^{\circ} \mathrm{C}$, spherical crystals of $\beta$-wollastonite can also be formed.

Wollastonite is the main crystalline phase of the commercial material known as Neoparies ${ }^{\mathbb{R}}$, which is manufactured from pure raw materials. This material is the first glass-ceramic

L. Pinckney — contributing editor

Manuscript No. 31275. Received March 30, 2012; approved July 18, 2012.

†Author to whom correspondence should be addressed. e-mail: mromero@ietcc.csic.es employed as construction material in building applications. The main characteristics of glass-ceramic materials include their wide range of compositions and the possibility of developing heterogeneous microstructures, which implies a lack of restriction in the amount of oxides that can be incorporated. This feature affords the possibility of using the glass-ceramic process for wastes valorization. In fact, the flexibility of this process is evidenced by the variety of mineral or industrial wastes that have been used as raw materials for the production of glass-ceramics, ${ }^{2,3}$ and these wastes include fly ashes from incineration ${ }^{4,5}$ and thermal power plants, ${ }^{6}$ wastes from hydrometallurgical processing plants, ${ }^{7}$ fiberglass wastes from polyester matrix composites, ${ }^{8}$ and rice husk ash. ${ }^{9}$ An advantage of including wastes in the production of glass-ceramic materials is the lower cost compared to using pure, raw materials. Moreover, wastes usually content in their chemical composition minor components, which when incorporated into a glassy network can act as nucleating agents favouring the crystallization process. ${ }^{10,11}$

Previously, Teixeira et al. ${ }^{12}$ have shown that a wollastonite glass-ceramic, similar to Neoparies ${ }^{\circledR}$, could be prepared using sugarcane bagasse ash as a silica source, thereby demonstrating the possibility of using waste valorization to develop suitable final properties for the industrial construction sector. They concluded that the crystallization of wollastonite occurs through a complex mechanism during heating. The results obtained by differential thermal analysis (DTA) indicated that bi-directional surface crystallization is the main route for glass devitrification. However, the kinetic study concluded that bulk crystallization occurs through the threedimensional growth of crystals and is the principal mechanism for wollastonite formation. Finally, scanning electron microscopy micrographs revealed that both processes occur simultaneously, i.e., crystallization began with the early surface crystallization of three-dimensional crystals that were subsequently transformed into needles (one-dimensional growth). The incomplete information obtained from the kinetic methods used in the former paper requires the need for a wider kinetic study that employs complex models that could explain the coexistence of both surface and bulk mechanisms during a single crystallization process.

The most commonly used methods for the kinetic analysis of solid-state reactions are the non-isothermal methods. There are several ways to study reactions under non-isothermal conditions. The activation energy is generally determined as a function of the reacted fraction, without using any previous assumptions in the kinetic model fitted to the reaction, by using isoconversional methods. Isokinetic methods assume that the transformation mechanism is the same throughout the temperature and time range of interest and that the kinetic parameters are supposed to be constant with respect to time and temperature. Master plots are well-known theoretical curves that depend on the reaction model and are 
independent of the Arrhenius parameters. The appropriate reaction model can be selected by comparison the experimental and theoretical master plots.

The Isokinetic Relationship (IKR) and Invariant Kinetic Parameters (IKP) methods have been widely applied to the study of the decomposition of aromatic azomonoethers, ${ }^{13}$ polymer curing, ${ }^{14}$ polymerization of poly(ester amide) potassium salt ${ }^{15}$ nickel oxide reduction study, ${ }^{16}$ and even to crystallization of silica-soda-lead glass ${ }^{17}$ and mullite development. ${ }^{18}$

The aim of the present work is to determine the kinetics parameters for the crystallization process of a wollastonite base glass. During this study, the isoconversional (integral and differential methods), IKR, and IKP methods were utilized. The experimental data were fit to integral and differential master plots, and finally, the present results are compared with those that were previously obtained using the Kissinger and Ligero methods. ${ }^{2}$

\section{Experimental Procedure}

\section{(1) Materials and Methods}

The wollastonite base glass studied here belongs to the $\mathrm{SiO}_{2}$ $\mathrm{Al}_{2} \mathrm{O}_{3}-\mathrm{CaO}-\mathrm{Na}_{2} \mathrm{O}$ system, and its preparation and chemical composition have been described by Teixeira et al. ${ }^{12}$

Differential thermal analysis was performed using a SETARAM Labsys Thermal Analyzer. The samples were analyzed in platinum crucibles with calcined $\mathrm{Al}_{2} \mathrm{O}_{3}$ as a reference material from room temperature to $1523 \mathrm{~K}$ at heating rates of $5,10,20,30,40$, and $50 \mathrm{~K} / \mathrm{min}$. The obtained data were analyzed using the Friedman ${ }^{19}$ and Kissinger-AkahiraSunose $^{20,21}$ isoconversional methods; the IKR, IKP, and the integral and differential master plots as it is described below.

\section{(2) Kinetic Methods}

(A) Isoconversional Methods: The employed isoconversional methods are based on dynamic DTA. The equation for the reaction rate used to study the degree of crystallization can generally be expressed as:

$$
\frac{\mathrm{d} \alpha}{\mathrm{d} t}=k(T) \cdot f(\alpha)
$$

where $\alpha$ is the extent of the reaction, $k(T)$ is the rate constant expressed by the temperature-dependent Arrhenius equation and $f(\alpha)$ is the reaction model function. Taking into account that under non-isothermal conditions, $\mathrm{d} \alpha / \mathrm{d} t=\beta$ $(\mathrm{d} \alpha / \mathrm{d} T)$, where $\beta$ is the heating rate $(\mathrm{K} / \mathrm{min})$, Eq. (1) can be rewritten as:

$$
\beta \cdot \frac{\mathrm{d} \alpha}{\mathrm{d} T}=A \cdot \mathrm{e}^{-E_{\mathrm{a}} / R \cdot T} \cdot f(\alpha)
$$

where $T$ is the temperature, $A$ is the pre-exponential factor, $R$ is the gas constant, and $E_{\mathrm{a}}$ is the activation energy, which is independent of conversion.

By taking the logarithm of each side of Eq. (2), the Friedman differential isoconversional method is obtained as follows:

$$
\ln \left(\frac{\mathrm{d} \alpha}{\mathrm{d} t}\right)=\ln [A \cdot f(\alpha)]-\frac{E_{\mathrm{a}}}{R \cdot T}
$$

and the rate equation can be expressed in its integral form as:

$$
g(\alpha)=\int_{0}^{\alpha} \frac{\mathrm{d} \alpha}{f(\alpha)}=\frac{A}{\beta} \int_{0}^{T} \mathrm{e}^{\left(-E_{\mathrm{a}} / R \cdot T\right)} \mathrm{d} T
$$

Assuming that the p-Doyle function, ${ }^{22} p\left(E_{\mathrm{a}} / R T\right)$, can be expressed using the Murray and White approximation, ${ }^{23}$ the
Kissinger-Akahira-Sunose (KAS) model-free method can be originally obtained by applying the following equation:

$$
\ln \left(\frac{\beta}{T^{2}}\right)=\ln \left(\frac{R \cdot A}{E_{\mathrm{a}} \cdot g(\alpha)}\right)-\frac{E_{\mathrm{a}}}{R} \cdot \frac{1}{T}
$$

In this case, the method does not require knowledge of the conversion-dependent functions $(f(\alpha)$ or $g(\alpha))$, and the only assumption is that the process follows the same reaction mechanism for a given degree of conversion, regardless of the crystallization temperature.

(B) Model Fitting Methods: These methods obtain the kinetic parameters with a single heating rate. In this work, the methods that have been employed are as follows:

-the integral method, known as the Coats-Redfern $(\mathrm{C}-\mathrm{R})$ $\operatorname{method}^{24}$ :

$$
\ln \left[\frac{g(\alpha)}{T^{2}}\right]=\ln \left[\frac{A \cdot R}{\beta \cdot E_{\mathrm{a}}}\right]-\frac{E_{\mathrm{a}}}{R \cdot T}
$$

-the differential method $(D)$, which is based on Eq. (3):

$$
\ln \left[\frac{\mathrm{d} \alpha / \mathrm{d} t}{f(\alpha)}\right]=\ln A-\frac{E_{\mathrm{a}}}{R \cdot T}
$$

For a given model (see Table I in Ref. 18) and heating rate, the linear plot of the left-hand sides vs $T^{-1}$ permitted the determination of $E_{\mathrm{a}}$ and $A$ from the slope and the intercept, respectively.

(C) Compensation Effect: The activation energy and the pre-exponential factor may be combined due to the so-called compensation effect or IKR through ${ }^{25,26}$ :

$$
\ln A_{x}=\alpha^{*}+\beta^{*} E_{x}
$$

where $\alpha^{*}$ and $\beta^{*}$ are constants and the subscripts, $x$, refer to a factor that produces a change in the Arrhenius parameters (conversion, heating rate and model). The intercept, $\alpha^{*}=\ln$ $k_{\text {iso }}$, is related to the isokinetic rate constant $\left(k_{\text {iso }}\right)$, and the slope, $\beta^{*}=1 / R T_{\text {iso }}$, is related to the isokinetic temperature $\left(T_{\text {iso }}\right)$. The appearance of the IKR indicates that only one mechanism is present, whereas the existence of parameters that do not agree with the IKR implies that there are multiple reaction mechanisms. ${ }^{26}$

According to certain authors, ${ }^{25}$ we may select the model whose IKR, in relation to the conversion, has the best linear correlation and in which the associated $T_{\text {iso }}$ value was near the experimental temperature range.

(D) Invariant Kinetic Parameters Method: The IKP $\operatorname{method}^{27,28}$ is based on the observation that the experimental curve, $\alpha(T)$, could be approximately correct when described by several conversion functions. By using the apparent compensatory effect that exists when the model changes for each heating rate $\left(\beta_{v}, v=1,2,3 \ldots\right)$, the compensation parameters, $\alpha_{v}{ }^{*}$ and $\beta_{v}{ }^{*}$, are determined according to Eq. (8). A set of conversion functions, $f_{j}$, where $j=1,2,3 \ldots$, are also considered (Table I in Ref. 18). For each heating rate, $\beta_{v}$ and the pairs $\left(\mathrm{A}_{v j}, \mathrm{E}_{v j}\right)$ that are characteristic of each conversion are determined using an integral or differential method. In this work, the integral method suggested by $\mathrm{C}-\mathrm{R}$ [Eq. (6)] and the differential method based on Eq. (7) will be used.

A plot of each of these equations should be a straight line formed from $\ln \left(A R / \beta E_{a}\right)$ or $\ln A$ respectively, and $\left(-E_{\mathrm{a}} / R\right)$.

Using the apparent compensation effect relationship, the compensation parameters $\left(\alpha^{*}, \beta^{*}{ }_{v}\right)$ are determined for each heating rate. The intersection point of the straight lines corresponds to the true values of $A$ and $E$. These were called the invariant parameters ( $\left.A_{\text {inv }}, E_{\text {ainv }}\right)$ by Lesnikovich and 
.000080808080

$\tau_{\mathscr{T}}$

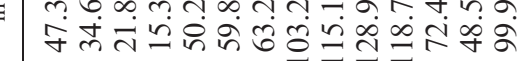

$\infty$

\section{音}

可

-

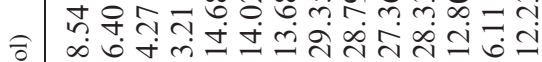

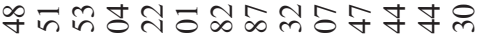

[uㅍ

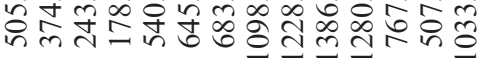

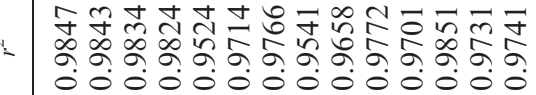

\begin{tabular}{|c|c|}
\hline $\begin{array}{l}\hat{T}_{\infty}^{\infty} \\
\widetilde{T} \\
\Xi\end{array}$ & 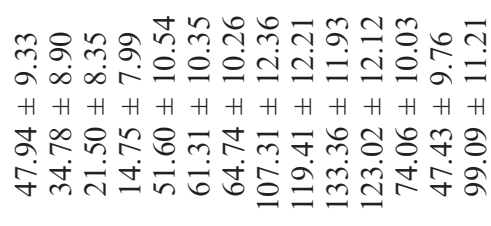 \\
\hline 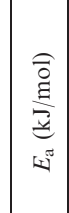 & 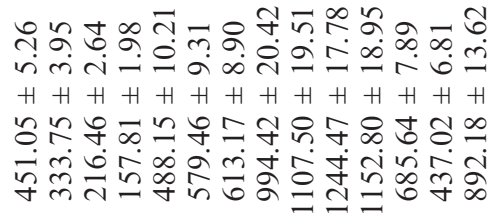 \\
\hline
\end{tabular}

$\overline{\bar{v}}$

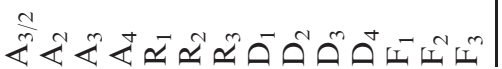

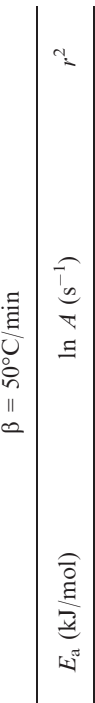

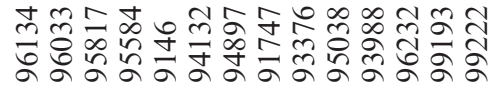

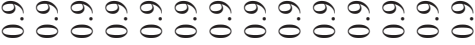

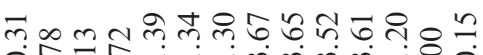

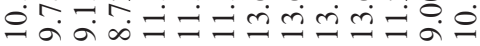
$H+H+H+H+H+H H H+H+H$

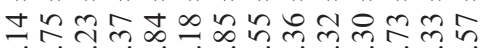

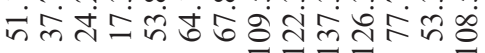

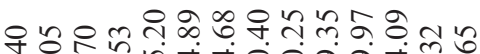

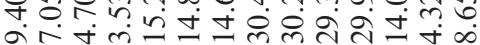
$H+H+H+H+H+H+H H+H$

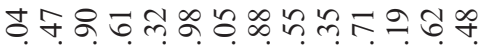
安宓

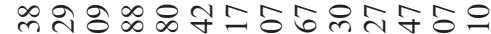

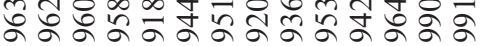

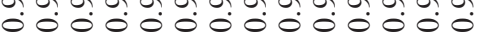

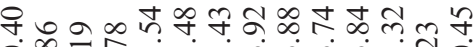

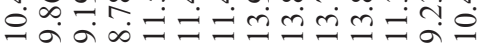
$H+H+H+H+H H H+H+H$ 舟

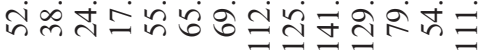

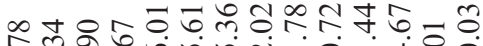
जिं $H+H+H+H+H+H+H+H+H$

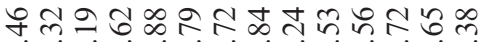

字市

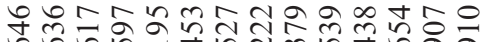

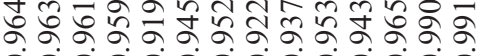
०००00000000000

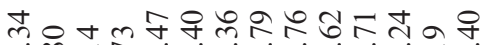

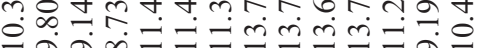
$H+H+H H H+H H H H+H$ m 늉ำ กं $\infty$

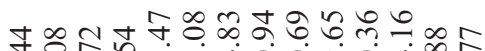

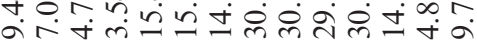
$H+H+H+H+H+H+H+H+H+$ 『

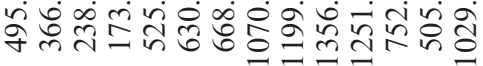

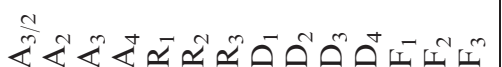


Table II. Integral Parameters Determined by Using the Differential [Eq. (7)] Method

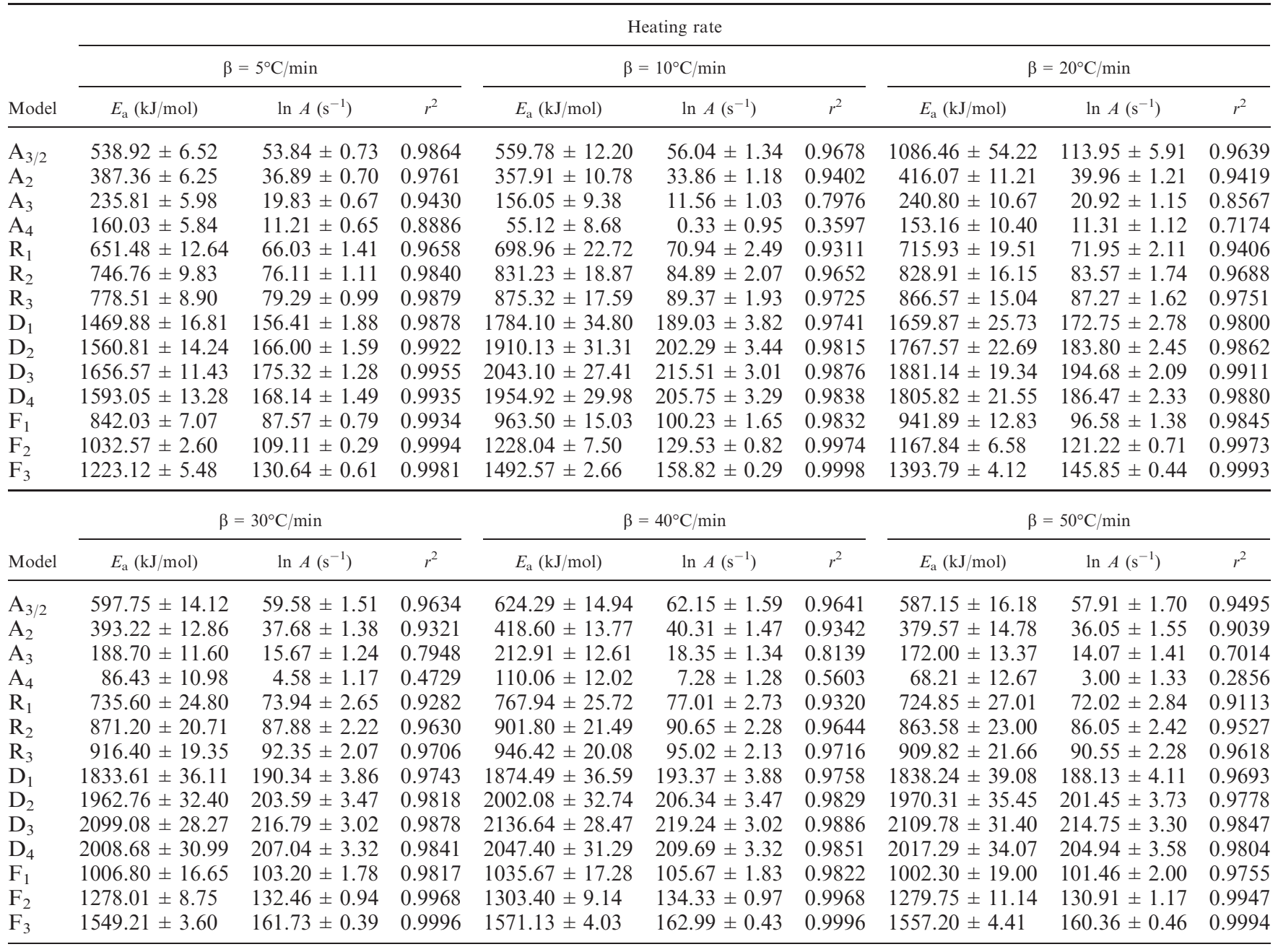

Levchnik, ${ }^{27,28}$ as they are independent of the conversion, the model and the heating rate. The evaluation of the invariant activation parameters is performed from the supercorrelation:

$$
\alpha_{v}^{*}=\ln A_{\text {inv }}-\beta_{v}^{*} E_{\text {ainv }}
$$

The straight line, $\alpha_{v}{ }^{*}$ vs $\beta_{v}{ }^{*}$, allows us to determine the IKP ( $E_{\text {ainv }}$ and $A_{\text {inv }}$ ) from the slope and intercept.

It has been reported that the values of the invariant conversion function are proportional to their true values. ${ }^{29,30}$ Therefore, the IKP method aims to determine the invariant parameters independent of the kinetic model; comparing the invariant parameters to those obtained using other methods also allows us to determine which kinetic model is better for describing the process.

(E) Master Plots: Recently, the as-known master plots are becoming increasing employed for the determination of the reaction models for solid-state reactions. The master plots are curves of the theoretical function of the reaction model and are independent of the Arrhenius parameters. The experimental kinetic data can easily be transformed into master plots, and the comparison between the theoretical and the experimental master plot leads to the selection of the appropriate reaction model, or at least, the appropriate type of kinetic model. There are two types of master plots: differential and integral. From Eqs. (3) and (4), for differential and integral plots, respectively, using a reference at point $\alpha=0.5$, the equations that are obtained are as follows:

$$
\begin{aligned}
& \frac{f(\alpha)}{f(0.5)}=\frac{(\mathrm{d} \alpha / \mathrm{d} \theta)}{(\mathrm{d} \alpha / \mathrm{d} \theta)_{\alpha=0.5}} \\
& \frac{g(\alpha)}{g(0.5)}=\frac{p(x)}{p\left(x_{0.5}\right)}
\end{aligned}
$$

where $p(x)=\frac{\mathrm{e}^{-x}}{x} \pi(x) ; p(x)$ has been obtained in the present article according to the Senum-Yang approximation. ${ }^{31}$ The plot of $f(\alpha) / f(0.5)$ versus $\alpha$ corresponds to the differential theoretical master plot, and the plot of $g(\alpha) / g(0.5)$ versus $\alpha$ corresponds to the integral theoretical master plot (details can be found in Refs. 32 and 33). Information regarding the temperature as a function of $\alpha$ and the value of $E_{\mathrm{a}}$ must be known in advance to construct the experimental master plots for a given heating rate (additional explanation can be found in Refs. 32-36).

\section{Results and Discussion}

As previously mentioned, Teixeira et al. ${ }^{12}$ have studied the crystallization of a wollastonite base glass using the Kissinger and Ligero methods. ${ }^{37}$ In the present article, the same data from the original experiments have been reassessed, and $E_{\mathrm{a}}$ and $\ln \mathrm{A}$ have been determined using several kinetic methods, specifically the isoconversional (KAS and Friedman) model fitting for a single, linear single heating rate, the IKR method employed under $f(\alpha)$, and heating rate variations, and the IKP method used with the integral and differential methods. 
Once the $E_{\text {ainv }}$ and $\ln A_{\text {inv }}$ parameters were obtained by using the IKP method, master plots were used to fit the experimental data using several functions of conversion.

\section{(1) Isoconversional Methods}

Figure 1 shows the variation of the activation energy with the degree of crystallization, $(\alpha)$. From this figure, it can be observed that the KAS and Friedman methods yield $E_{\mathrm{a}}$ values that are somewhat different over all $\alpha$ ranges, although they are on the same order of magnitude. These differences may be because the models are derived from different calculations of Eq. (2), as reported by other authors. ${ }^{14}$ All $E_{\text {a }}$ values determined from both methods exhibit standard errors lower than $10 \%$. However, the results obtained using the Friedman method resulted in larger errors than those from the KAS method, as the way $E_{\mathrm{a}}$ is obtained from the Friedman method is more sensitive to noise from DTA thermograms. ${ }^{36}$ The shapes of the $E_{\mathrm{a}}$ curves depicted from the two models are rather different, which could indicate the existence of more than one crystallization mechanism that fits the experimental results.

For the KAS method, the $E_{\mathrm{a}}$ values are approximately constant for $\alpha=0.15-0.80$, whereas for the Friedman method, $E_{\mathrm{a}}$ can be considered constant in the range of 0.1-0.45. Nevertheless, the curves in Fig. 1 exhibit a similar trend. The first part, where $E_{\mathrm{a}}$ is constant, indicates that crystallization occurs through a single mechanism; then, the change in $E_{\mathrm{a}}$ with increasing $\alpha$ reveals that the crystallization reaction changes to a multiple-step mechanism. The mean activation energy values that are determined in the intervals where $E_{\mathrm{a}}$ is constant are $E_{\mathrm{aKAS}}=357 \pm 6 \mathrm{~kJ} / \mathrm{mol}$ and $E_{\text {aFriedman }}=386 \pm 5 \mathrm{~kJ} / \mathrm{mol}$. Both values are in agreement with those reported by Teixeira et al. ${ }^{12}$ from application of the Kissinger and Ligero methods (374 and $378 \mathrm{~kJ} / \mathrm{mol}$ ).

It is shown in Fig. 1 that $E_{\mathrm{a}}$ is independent of the degree of crystallization in the range of $0.15-0.80$ for the KAS and 0.05-0.45 for the Friedman methods. Model fitting, IKR, and IKP have been applied across those intervals.

\section{(2) Model Fitting Methods}

Tables I and II provide the results after application of the integral C-R [Eq. (6)] and the differential (D) [Eq. (7)] methods, respectively. It can be observed that a wide variety of results depend on the applied mechanism. If the collected $E_{\mathrm{a}}$ values shown in Tables I and II are compared with those determined previously using the isoconversional methods (357 and $386 \mathrm{~kJ} / \mathrm{mol}$ ), the function that yields a better fit to

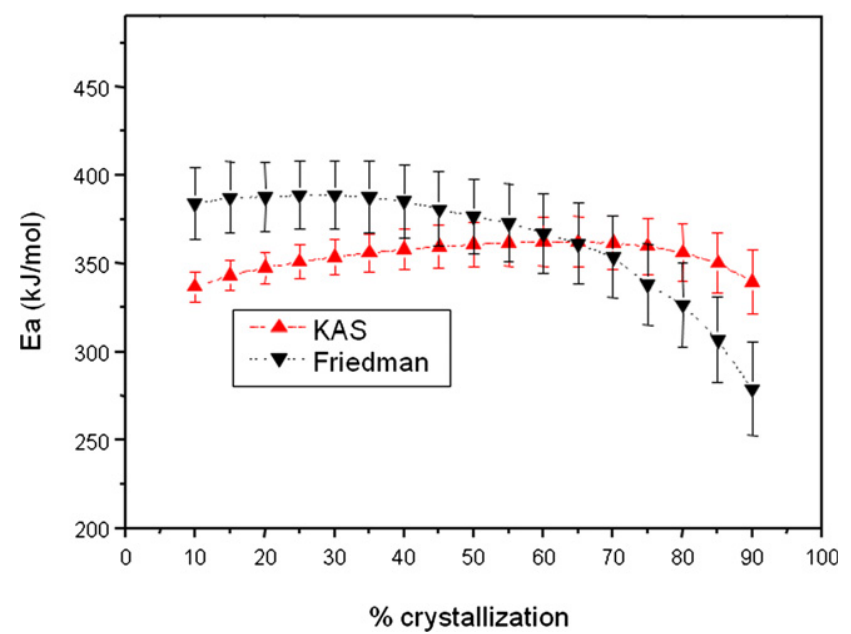

Fig. 1. Variation of activation energy with crystallization degree obtained by Friedman and KAS isoconversional methods. the experimental results corresponds to the Avrami mechanism, $\mathrm{A}_{2}$, for both the $\mathrm{C}-\mathrm{R}$ and $\mathrm{D}$ methods. Nevertheless, the $E_{\mathrm{a}}$ values that were determined from the DTA thermograms using different heating rates vary noticeably, which indicates that the wollastonite crystallization process cannot be adjusted to any of the mechanisms shown in Tables I and II. Therefore, these results suggest that there should be a more complex mechanism for the explanation of the crystallization process.

\section{(3) IKR Method}

Tables III and IV show the correlation parameters from applying Eq. (8) to each mechanism for all heating rates. As previously explained, the values of $T_{\text {iso }}$ can be obtained from the slope, $\beta^{*}$. The most appropriate mechanism for the explanation of the crystallization process will be the one whose $T_{\text {iso }}$ was within the devitrification experimental range as shown from the original DTA thermogram $\left(800^{\circ} \mathrm{C}-950^{\circ} \mathrm{C}\right)$. In addition, the fit must have a good regression coefficient $\left(R^{2}>0.9\right)$ using the proposed mechanism. ${ }^{14,25}$ The integral results (Table III) show that the temperatures, $T_{\text {iso }}$, for the $\mathrm{A}_{3 / 2}, \mathrm{~A}_{2}, \mathrm{R}_{n}$, and $\mathrm{F}_{n}$ mechanisms are in the same range as experimental results; therefore, there is more than one mechanism that can fit the crystallization process. In the case of differential values (Table IV), the mechanisms that best fit $T_{\text {iso }}$ are $A_{n}$. These results also confirm that the crystallization occurs through a complex mechanism.

Table III. Integral Isokinetic Parameters Determined from Eq. (8) for Different Reaction Mechanisms

\begin{tabular}{lcccc}
\hline Model & $\alpha^{*}\left(\mathrm{~min}^{-1}\right)$ & $\beta^{*}(\mathrm{~mol} / \mathrm{kJ})$ & $r^{2}$ & $T_{\text {iso }}\left({ }^{\circ} \mathrm{C}\right)$ \\
\hline $\mathrm{A}_{3 / 2}$ & $-2.8416 \pm 3.3063$ & $0.1114 \pm 0.0068$ & 0.9817 & 806.5 \\
$\mathrm{~A}_{2}$ & $-2.5033 \pm 0.7012$ & $0.1119 \pm 0.0019$ & 0.9985 & 802.0 \\
$\mathrm{~A}_{3}$ & $-2.2251 \pm 2.1596$ & $0.1125 \pm 0.0092$ & 0.9673 & 795.8 \\
$\mathrm{~A}_{4}$ & $-2.1193 \pm 3.3575$ & $0.1128 \pm 0.0197$ & 0.8647 & 792.9 \\
$\mathrm{R}_{1}$ & $-0.9180 \pm 3.8588$ & $0.1068 \pm 0.0075$ & 0.9757 & 853.3 \\
$\mathrm{R}_{2}$ & $0.6546 \pm 5.8856$ & $0.1036 \pm 0.0096$ & 0.9586 & 887.6 \\
$\mathrm{R}_{3}$ & $1.1205 \pm 6.5832$ & $0.1026 \pm 0.0101$ & 0.9533 & 898.8 \\
$\mathrm{D}_{1}$ & $6.6228 \pm 16.7912$ & $0.0994 \pm 0.0161$ & 0.8819 & 936.9 \\
$\mathrm{D}_{2}$ & $9.0797 \pm 19.0171$ & $0.0977 \pm 0.0163$ & 0.8755 & 957.4 \\
$\mathrm{D}_{3}$ & $11.4652 \pm 21.4915$ & $0.0961 \pm 0.0163$ & 0.8714 & 978.6 \\
$\mathrm{D}_{4}$ & $8.8737 \pm 19.8477$ & $0.0971 \pm 0.0163$ & 0.8739 & 965.0 \\
$\mathrm{~F}_{1}$ & $4.1205 \pm 8.0102$ & $0.1008 \pm 0.0110$ & 0.9436 & 920.2 \\
$\mathrm{~F}_{2}$ & $1.0560 \pm 2.0367$ & $0.1058 \pm 0.0042$ & 0.9922 & 863.7 \\
$\mathrm{~F}_{3}$ & $12.3848 \pm 9.3041$ & $0.0962 \pm 0.0094$ & 0.9540 & 976.7 \\
\hline
\end{tabular}

Table IV. Differential Isokinetic Parameters Determined from Eq. (8) for Different Reaction Mechanisms

\begin{tabular}{lcccr}
\hline Model & $\alpha^{*}\left(\mathrm{~min}^{-1}\right)$ & $\beta^{*}(\mathrm{~mol} / \mathrm{kJ})$ & $r^{2}$ & $T_{\text {iso }}\left({ }^{\circ} \mathrm{C}\right)$ \\
\hline $\mathrm{A}_{3 / 2}$ & $-6.4436 \pm 0.8699$ & $0.1107 \pm 0.0013$ & 0.9994 & 813.4 \\
$\mathrm{~A}_{2}$ & $-4.2251 \pm 0.6018$ & $0.1063 \pm 0.0015$ & 0.9990 & 858.2 \\
$\mathrm{~A}_{3}$ & $-4.0816 \pm 1.2098$ & $0.1035 \pm 0.0060$ & 0.9837 & 888.5 \\
$\mathrm{~A}_{4}$ & $-4.3957 \pm 0.7539$ & $0.1012 \pm 0.0067$ & 0.9786 & 915.0 \\
$\mathrm{R}_{1}$ & $6.0225 \pm 4.0315$ & $0.0922 \pm 0.0056$ & 0.9816 & 1032.1 \\
$\mathrm{R}_{2}$ & $7.5432 \pm 4.7039$ & $0.0920 \pm 0.0056$ & 0.9818 & 1034.5 \\
$\mathrm{R}_{3}$ & $7.7268 \pm 4.9480$ & $0.0921 \pm 0.0056$ & 0.9818 & 1032.8 \\
$\mathrm{D}_{1}$ & $20.5662 \pm 11.3857$ & $0.0924 \pm 0.0065$ & 0.9757 & 1028.4 \\
$\mathrm{D}_{2}$ & $21.2722 \pm 12.0472$ & $0.0927 \pm 0.0065$ & 0.9763 & 1024.2 \\
$\mathrm{D}_{3}$ & $21.2478 \pm 12.7430$ & $0.0930 \pm 0.0064$ & 0.9768 & 1020.5 \\
$\mathrm{D}_{4}$ & $20.2632 \pm 12.2805$ & $0.0928 \pm 0.0064$ & 0.9765 & 1022.9 \\
$\mathrm{~F}_{1}$ & $9.9191 \pm 5.4452$ & $0.0924 \pm 0.0056$ & 0.9817 & 1028.5 \\
$\mathrm{~F}_{2}$ & $12.9976 \pm 6.9401$ & $0.0932 \pm 0.0057$ & 0.9816 & 1017.0 \\
$\mathrm{~F}_{3}$ & $16.0591 \pm 8.4151$ & $0.0938 \pm 0.0057$ & 0.9816 & 1009.4 \\
\hline
\end{tabular}


Table V. Values of Integral and Differential Compensation Parameters Calculated from Data in Tables I and II

\begin{tabular}{|c|c|c|c|c|c|c|c|c|}
\hline$\beta\left({ }^{\circ} \mathrm{C} / \mathrm{min}\right)$ & \multicolumn{4}{|c|}{ Integral } & \multicolumn{4}{|c|}{ Differential } \\
\hline 5 & $-1.5752 \pm 0.7013$ & $0.1093 \pm 0.0009$ & 827 & 0.9991 & $-5.6905 \pm 0.5156$ & $0.1100 \pm 0.0005$ & 821 & 0.9997 \\
\hline 20 & $-0.3125 \pm 0.7163$ & $0.1057 \pm 0.0010$ & 865 & 0.9989 & $-4.1696 \pm 0.6798$ & $0.1064 \pm 0.0006$ & 857 & 0.9996 \\
\hline 30 & $0.1546 \pm 0.7240$ & $0.1050 \pm 0.0009$ & 872 & 0.9991 & $-3.8704 \pm 0.4805$ & $0.1057 \pm 0.0004$ & 865 & 0.9998 \\
\hline 40 & $0.4258 \pm 0.7259$ & $0.1042 \pm 0.0009$ & 882 & 0.9991 & $-3.5644 \pm 0.4858$ & $0.1048 \pm 0.0004$ & 874 & 0.9998 \\
\hline
\end{tabular}

Table $\mathrm{V}$ shows the integral and differential compensation parameters determined from applying Eq. (8) to the data in Tables I and II. At each heating rate, the mechanisms that resulted in better fits to the experimental results have been considered for calculations. In this case, all the $T_{\text {iso }}$ values are within the experimental wollastonite crystallization range, and furthermore, the regressions are better than those presented in Tables III and IV.

Taking the data collected in Tables III-V into account, it can be observed that the IKR method is unable to establish an appropriate model for this crystallization process.

\section{(4) IKP Method}

The IKP obtained from Table V by applying Eq. (9) are $E_{\text {ainv }}=386 \pm 20 \mathrm{~kJ} / \mathrm{mol}$ and $\ln A_{\text {inv }}=37 \pm 2$ for the differential model and $E_{\text {ainv }}=362 \pm 23 \mathrm{~kJ} / \mathrm{mol}$ and $\ln A_{\text {inv }}=38 \pm 2$ for the integral model. It can be seen that both $E_{\text {ainv }}$ and $\ln A_{\text {inv }}$ determined from the integral and differential models are similar.

The $E_{\text {ainv }}$ and $\ln A_{\text {inv }}$ values are in agreement with those reported in the previous paper ${ }^{12}$ and are also similar to the values calculated for model $\mathrm{A}_{2}$ (Tables I and II).

\section{(5) Master Plots}

Master plots that have been drawn to verify the model, or models, result in better fits to the experimental results. Figure 2 shows the results of the differential master plot from the application of Eq. (10). The theoretical curves drawn $\left(A_{3 / 2}, A_{2}\right.$, and $\left.F_{1}\right)$ are those that yielded the best fits to experimental data. For degrees of crystallization lower than 0.5 , the experimental curve depicts a trend similar to

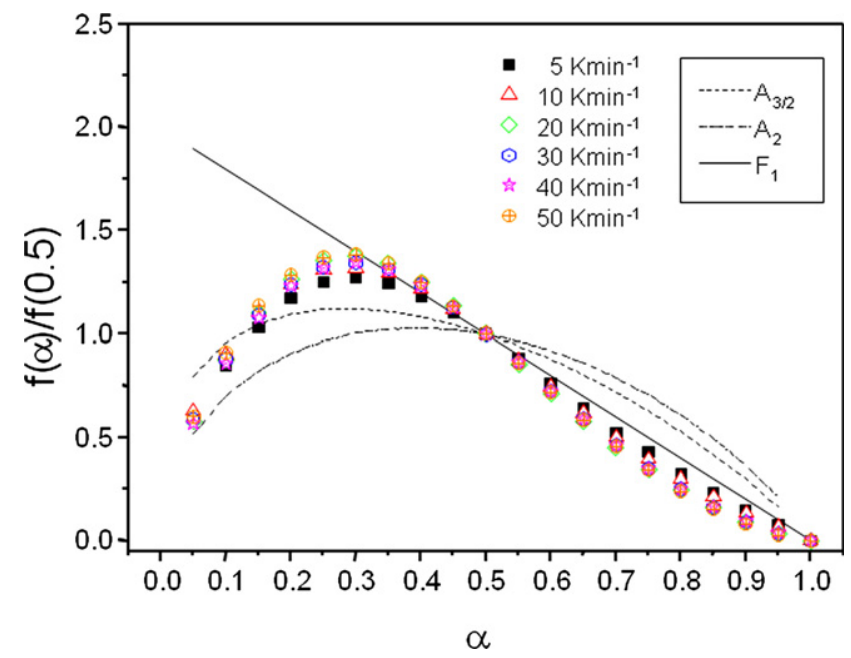

Fig. 2. Theoretical (lines) differential master plots of $f(\alpha) / f(0.5)$ vs $\alpha$ and the experimental master curve (symbols). the Avrami $\left(\mathrm{A}_{3 / 2}\right.$ and $\left.\mathrm{A}_{2}\right)$ theoretical curves, whereas at higher conversion degrees, the mechanism that yield the best fit is $F_{1}$, which indicates a first-order reaction that is coincident with the Avrami mechanism for surface crystallization. These results disagree with those previously obtained using the isoconversional Friedman method. In Fig. 1, the $E_{\mathrm{a}}$ determined from the Friedman method is constant in the range of $0.05-0.45$, whereas the master plot (Fig. 2) shows an unfitted Avrami-like mechanism. For $\alpha>0.45$, the $F_{1}$ mechanism results in a better fit in the master plot, but Fig. 1 shows that this range corresponds to a multiple-step mechanism. Therefore, the wollastonite crystallization mechanism cannot be obtained by applying the Friedman method and differential master plot together.

Figure 3 presents the integral master plot obtained by applying Eq. (11). Similar to Fig. 2, only the theoretical curves that resulted in better fits $\left(\mathrm{A}_{3 / 2}, \mathrm{~A}_{2}, \mathrm{~A}_{3}\right.$, and $\left.\left.\mathrm{F}_{1}\right)\right)$ are shown along with the experimental results. In this case, the theoretical curve that corresponds to $\mathrm{A}_{3}$ mechanism is best fitted in the $\alpha=0.05-0.4$ interval, whereas from 0.4 to 0.8 , the crystallization is adjusted for the $A_{3 / 2}$ mechanism. These results indicate a complex mechanism of three-dimensional growth of crystals with a constant number of nuclei $\left(A_{3}\right)$ in the surface of the glass particles, and subsequently volume crystallization, originated from the one-dimensional growth of needles by diffusion control $\left(\mathrm{A}_{3 / 2}\right)$ from the surface to the interior of glass particles.

As final remark, it can be said that the kinetic methods applied in this study indicate a complex crystallization mechanism that agrees with the results previously reported by Teixeira et al. ${ }^{12}$ i.e., the initial development of a crystallization shell that is composed of spherulitic crystal (threedimensional) followed by the growth of linear fiber-like crystals into the glass sample.

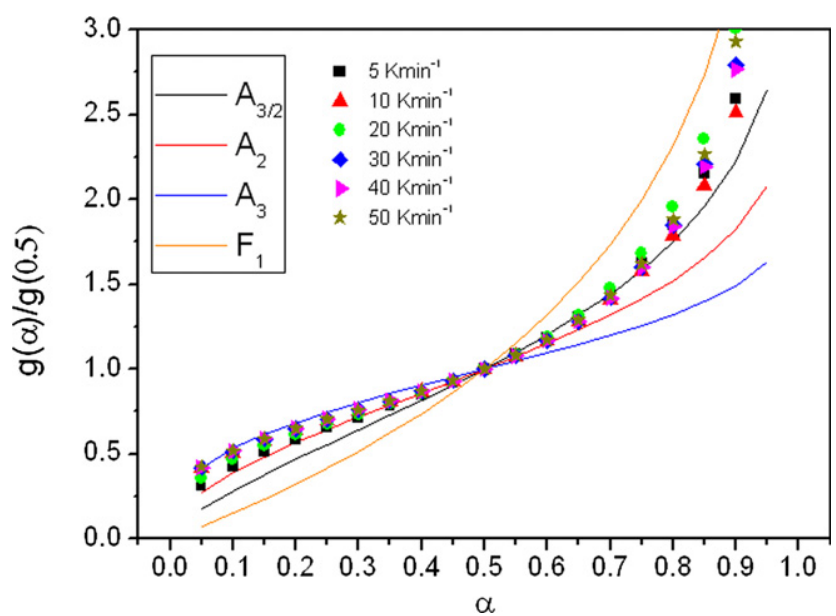

Fig. 3. Theoretical (lines) integral master plots of $g(\alpha) / g(0.5)$ vs $\alpha$ and the experimental master curve (symbols). 


\section{Conclusions}

The complex crystallization mechanism of a wollastonite glass has been established from a non-isothermal kinetic study by means of DTA. This study has allowed the determination of the activation energy $\left(E_{\mathrm{a}}\right)$, pre-exponential factor $(A)$ and, when possible, the function of conversion $(f(\alpha))$. To assess the crystallization mechanism (single and/or multiple steps), both the integral KAS method and the differential Friedman isoconversional methods were used. The isokinetic temperature $\left(T_{\text {iso }}\right)$ was determined from the IKR, whereas the Isokinetic Parameters method was used to obtain both the invariant activation energy $\left(E_{\text {ainv }}\right)$ and the pre-exponential factor $\left(A_{\text {inv }}\right)$. To determine the $f(\alpha)$, the Master Plots (differential and integral) were applied.

The activation energies, which were determined using the isoconversional methods, are in range $360-386 \mathrm{~kJ} / \mathrm{mol}$. These values agree with the IKP, which were obtained from the application of both integral $\left(E_{\text {ainv }}=362 \mathrm{~kJ} / \mathrm{mol}\right)$ and differential $\left(E_{\text {ainv }}=386 \mathrm{~kJ} / \mathrm{mol}\right)$ methods.

Isoconversional methods have revealed that the crystallization process occurs in two stages, a first step that has constant activation energy (single step mechanism) followed by a later step that is characterized by the variation of activation energy with the conversional degree (multi-step mechanism).

Master plots indicate that the wollastonite crystallization takes place through a complex mechanism. In the $\alpha=0.05$ 0.4 interval, the three-dimensional growth of crystals with a constant number of nuclei $\left(\mathrm{A}_{3}\right)$ occurs on the surface of the glass particles. Later, in the $\alpha=0.4-0.8$ interval, the crystallization is adjusted to the $A_{3 / 2}$ mechanism, which means that one-dimensional growth of needles occurs by diffusion control from the surface to the interior of glass particles.

\section{Acknowledgments}

One of the authors (J.M. Pérez) would like to acknowledge CSIC for the financial support by contract JAEDoc-08-00362. S.R. Teixeira is greatly indebted to FAPEST (04368-4/08 and to UNESP/PROPE-SANTANDER postdoc program for the scholarship.

\section{References}

${ }^{1}$ R. D. Rawlings, J. P. Wu, and A. R. Boccaccini, "Glass-Ceramics: Their Production from Wastes- A Review," J. Mater. Sci., 41 [3] 733-61 (2006).

${ }^{2}$ W. Höland and G. Beall, Glass-Ceramic Technology. The American Ceramic Society, Westerville, OH, 2002

${ }^{3}$ M. Romero and J. Ma. Rincón, "The Controlled Vitrification/Crystallisation Process Applied to the Recycling of Inorganic Industrial Wastes," Bol. Soc. Esp. Ceram. Vid., 39 [1] 155-63 (2000).

${ }^{4}$ M. S. Hernandez-Crespo, M. Romero, and J. Ma. Rincón, "Nucleation and Crystal Growth of Glasses Produced by a Generic Plasma Arc-Process," J. Eur. Ceram. Soc., 26 [9] 1679-85 (2006)

${ }^{5}$ M. Romero, M. S. Hernández-Crespo, and J. Ma. Rincón, "Leaching Behaviour of a Glassy Slag and Derived Glass Ceramics from Arc Plasma Vitrification of Hospital Wastes," Adv. Appl. Ceram., 108 [1] 67-71 (2009).

${ }^{6}$ L. Barbieri, I. Lancellotti, T. Manfredini, G. C. Pellacani, J. Ma. Rincón, and M. Romero, "Nucleation and Crystallization of New Glasses from Fly Ash Originating from Thermal Power Plants," J. Am. Ceram. Soc., 84 [8] 1851 -8 (2001).

M. Romero, M. Kovacova, and J. Ma. Rincón, "Effect of Particle Size on Kinetics Crystallization of an Iron-Rich Glass," J. Mater. Sci., 43 [12] 4135 42 (2008).

${ }^{8}$ F. A. López, M. I. Martín, F. J. Alguacil, J. Ma. Rincón, T. A. Centeno, and M. Romero, "Thermolysis of Fibreglass Polyester Composite and Reutilisation of the Glass Fibre Residue to Obtain a Glass-Ceramic Material," $J$. Anal. Appl. Pyrol., 93 [1] 104-12 (2012).

${ }^{9}$ M. I. Martín, J. Ma. Rincón, F. Andreola, L. Barbieri, I. Lancellotti, and M. Romero, "Materiales Vitrocerámicos del Sistema $\mathrm{MgO}-\mathrm{Al}_{2} \mathrm{O}_{3}-\mathrm{SiO}_{2}$ a Partir de Ceniza de Cáscara de Arroz," Bol. Soc. Esp. Ceram. Vid., 50 [4] 201-6 (2011).

${ }^{10} \mathrm{~J}$. Ma. Rincón, "Principles of Nucleation and Controlled Crystallisation of Glasses," Polym. Plast. Technol. Eng., 31 [3-4] 309-57 (1992).
${ }^{11}$ M. Romero, R. D. Rawlings, and J. Ma. Rincón, "Crystal Nucleation and Growth in Glasses from Inorganic Wastes from Urban Incineration," J. Non-Cryst. Solids, 271 [1-2] 106-18 (2000).

${ }^{12} \mathrm{~S}$. R. Teixeira, M. Romero, and J. Ma. Rincón, "Crystallization of $\mathrm{SiO}_{2}-\mathrm{CaO}-\mathrm{Na}_{2} \mathrm{O}$ Glass Using Sugarcane Bagasse Ash as Silica Source," J. Am. Ceram. Soc., 93 [2] 450-5 (2010)

${ }^{13}$ A. Rotaru, A. Moanta, I. Sălăgeanu, P. Budrugeac, and E. Segal, "Thermal Decomposition Kinetics of Some Aromatic Azomonoethers. Part I. Decomposition of 4-[(4-Chlorobenxyl)oxy]-4'-Nitro-Azobenzene," J. Therm. Anal. Calorim., 87 [2] 395-400 (2007).

${ }^{14}$ A. Cadenato, J. M. Morancho, X. Fernández-Francos, J. M. Salla, and X. Ramis, "Comparative Kinetic Study of the Non-Isothermal Thermal Curing of Bis-GMA/TEGDMA Systems," J. Them. Anal. Calorim., 89 [1] 233-44 (2007)

${ }^{15}$ X. Ramis, J. M. Salla, and J. Puiggalí, "Kinetic Studies on the Thermal Polymerization of N-Chloroacetyl-11-Aminoundecanoate Potassium Salt," $J$ Polym. Sci. Part A, 43 [6] 1166-76 (2005).

${ }^{16}$ B. Jankovic, B. Adnadevic, and S. Mentus, "The Kinetic Analysis of NonIsothermal Nickel Oxide Reduction in Hydrogen Atmosphere Using the Invariant Kinetic Parameters Method," Thermochim. Acta, 456 [1] 48-55 (2007).

${ }^{17}$ O. C. Mocioiu, M. Zaharescu, G. Jitianu, and P. Budrugeac, "Kinetic Parameters Determination in Non-Isothermal Conditions for the Crystallization of A Silica-Soda-Lead Glass," J. Therm. Anal. Calorim., 86 [2] 429-36 (2006)

${ }^{18}$ J. M. Pérez, J. M. Rincón, and Ma. Romero, "Study of Mullite Formation in Porcelain Stoneware Applying Isoconversional and IKP Methods," Ceram. Int., 36 [8] 2329-35 (2010).

${ }^{19}$ H. L. Friedman, "Kinetics of Thermal Degradation of Char-Forming Plastics from Thermogravimetry. Application to a Phenolic Plastic," J. Polym. Sci. Part C, 6 [1] 183-95 (1964).

${ }^{20}$ H. E. Kissinger, "Reaction Kinetics in Differential Thermal Analysis," Anal. Chem., 29 [11] 1702-6 (1957).

${ }^{21} \mathrm{~T}$. Akahira and T. Sunose, "Joint Convention of Four Electrical Institutes," Res. Report Chiba. Inst. Technol., 16, 22-31 (1971).

${ }^{22}$ C. D. Doyle, "Estimating Thermal Stability of Experimental Polymers by Empirical Thermogravimetric Analysis," Anal. Chem., 33 [1] 77-9 (1961).

${ }^{23} \mathrm{P}$. Murray and J. White, "Kinetics of the Thermal De-Hydration of Clays," Trans. Br. Ceram. Soc., 54, 151-87 (1955).

${ }^{24}$ A. W. Coats and J. P. Redfern, "Kinetics Parameters from Thermogravimetric Data," Nature, 201, 68-9 (1964).

${ }^{25} \mathrm{~S}$. Vyazovkin and W. Linert, "False Isokinetic Relationships Found in the Nonisothermal Decomposition of Solids," Chem. Phys., 193 [1] 109-18 (1995).

${ }^{26} \mathrm{~S}$. Vyazovkin and W. Linert, "The Application of Isoconversional Methods for Analyzing Isokinetic Relationships Occurring at Thermal Decomposition of Solids," J. Solid State Chem., 114 [2] 392-8 (1995).

${ }^{27}$ A. I. Lesnikovich and S. V. Levchik, "A Method of Finding Invariant Values of Kinetic Parameters," J. Therm. Anal. Calorim., 27 [1] 89-94 (1983).

${ }^{28}$ A. I. Lesnikovich and S. V. Levchik, "Isoparametric Kinetic Relationship for Chemical Transformations in Condensed Substances (Analytical Survey) II. Reactions Involving the Participation of Solids Substances," J. Therm. Anal. Calorim., 30 [3] 667-702 (1985).

${ }^{29}$ P. Budrugeac, "Some Methodological Problems Concerning the Kinetic Analysis of Non-Isothermal Data for Thermal and Thermo-Oxidative Degradation of Polymers and Polymeric Materials," Polym. Degrad. Stab., 89 [2] 265-73 (2005).

${ }^{30} \mathrm{P}$. Budrugeac and E. Segal, "On the Kinetic Processing of Thermal Analysis Data," Rev. Roum. Chim., 49 [3-4] 193-8 (2004).

${ }^{31}$ G. I. Senum and R. T. Yang, "Rational Approximations of the Integral of the Arrhenius Function," J. Therm. Anal. Calorim., 11 [3] 445-7 (1977).

${ }^{32}$ F. J. Gotor, J. M. Criado, J. Malek, and N. Koga, "Kinetic Analysis of Solid-State Reactions: The Universality of Master Plots for Analysing Isothermal and Nonisothermal Experiments," J. Phys. Chem. A, 104 [46] 10777-82 (2000)

${ }^{33}$ J. M. Criado, L. A. Pérez-Maqueda, F. J. Gotor, J. Malek, and N. Koga, "A Unified Theory for the Kinetic Analysis of Solid State Reactions Under Any Thermal Pathway," J. Therm. Anal. Calorim., 72 [3] 901-6 (2003).

${ }^{34}$ J. M. Morancho, A. Cadenato, X. Fernández-Francos, J. M. Salla, and X. Ramis, "Isothermal Kinetics of Photopolymerization and Thermal Polymerization of bis-GMA/TEGDMA Resins," J. Therm. Anal. Calorim., 92 [2] 513-22 (2008)

${ }^{35}$ B. Janković, B. Adnadević, and J. Jovanović, "Application of Model-Fitting ad Model -Free Kinetics to the Study of Non-Isothermal Dehydration of Equilibrium Swollen Poly (Acrylic Acid) Hydrogel: Thermogravimetric Analysis," Thermochim. Acta, 452 [2] 106-15 (2007)

${ }^{36}$ S. Vyazovkin, A. K. Burham, J. M. Criado, L. A. Perez-Maqueda, C. Popescu, and N. Sbirrazzuolli, "ICTAC Kinetics Committee Recommendations for Performing Kinetic Computations on Thermal Analysis Data," Thermochim. Acta, 520 [1-2] 1-19 (2011).

${ }^{37}$ R. A. Ligero, J. Vázquez, M. Casa-Ruiz, and R. Jiménez-Garay, "A Study of the Crystallization Kinetics of Some Cu-As-Te Glasses," J. Mater. Sci., 26 [1] 211-5 (1991) 